\title{
Violence against the elderly: correlation with social support, depressive symptoms and sociodemographic characterization of an elderly population of the Brazilian Northeast
}

\begin{abstract}
The objective of this study was to correlate data on violence against the elderly with social support and depressive symptoms. Cross-sectional study carried out from October 2016 to May 2017 with a sample of 199 elderly people living in the community. Data were collected by means of: a) Socio-demographic Questionnaire, b) the Abuse Vulnerability Screening Scale (VASS-Br), c) the Geriatric Depression Scale (GDS-15), and d) the Social Support Scale (AND THE). The obtained data were categorized and analyzed through descriptive and inferential statistics. Most of the participants were women $(\mathrm{n}=141,70.9 \%)$, ranging in age from 60 to 84 years (M: 67.96; $\mathrm{SD}: \pm 6.45)$ with approximately one to eight persons at home (M : 4.07, DP: \pm 1.36$)$. The prevalence of violence among the elderly in the sample was $16 \%(n=31)$. Correlation between violence and depression was found only $(\mathrm{r}=0.540, \mathrm{p}<0.001)$. The findings point to the prevalence of violence and correlation with depressive symptoms similar to data already mentioned in the literature. However, it is emphasized that such data may be under-reported due to aspects such as the proximity bond and/or kinship of the aggressor with the victim or the dependency relations that exist in the victimaggressor relationship.
\end{abstract}

Keywords: aging, prevalence, depression, social support
Volume 3 Issue 6 - 2018

\section{Rodrigo da Silva Maia,Alessandra do Nascimento Cavalcanti, Eulália Maria Chaves Maia}

Department of Psychology, Federal University of Rio Grande do Norte, Brazil

\begin{abstract}
Correspondence: Rodrigo da Silva Maia, Department of Psychology, Federal University of Rio Grande do Norte, Av. Senador Salgado Filho, s/n, Lagoa Nova. Campus Universitário Lagoa Nova, CEP 59078-970, Brazil,Tel +558433422236(320), Email rodrego_maia89@yahoo.com.br
\end{abstract}

Received: August 31, 2018 | Published: November 27, 2018

\section{Introduction}

Population aging is a phenomenon experienced worldwide Associated with human aging, there has been an increase in the number of cases of mistreatment and violence against the elderly population. ${ }^{1}$ The large number of elderly people who have been victims of violence, neglect, mistreatment or discrimination are noteworthy. Violence permeates the spaces of social coexistence, occurring in the family, home or other social institutions, and the rights and citizenship of those who are affected by it are cruelly disrespected. ${ }^{2}$

Violence against the elderly can be classified as physical, psychological or emotional violence- including verbal violence sexual, economic or financial violence, neglect and self-neglect. ${ }^{3}$ Although violence against the elderly is a rising phenomenon, difficulties in screening, identifying and preventing violence have been identified. Among the reasons that lead the interdiction of information, the difficulty of denouncing and limiting the confrontation of violence, are related to the relationship between the abuser and the victim or the affective-emotional, care or financial dependency relationships that exist in the victim-aggressor relationship, for example. ${ }^{4-6}$

Biopsychosocial aspects have been associated with this phenomenon of violence. For example, aspects of physical and mental health, such as falling, being dependent on care or presenting depressive symptoms, are indicated as risk factors for the occurrence of violence against the elderly. Otherwise, having a social support network has been pointed out as a factor that prevents and protects the elderly against the occurrence of the phenomenon. ${ }^{2,4}$
Therefore, the present study aims to correlate data on violence against the elderly with social support and depressive symptoms, and to characterize the sociodemographic aspects of a sample of the elderly in the Brazilian Northeast.

\section{Methods}

Cross-sectional study carried out from October 2016 to May 2017 with a sample of 199 elderly people living in the community. Elderly patients (60 years of age or older), who had the ability to verbalize and who had their mental functions preserved, were included in the sample. The data were collected individually through an interview and questionnaire application.

The research protocol was composed of the following instruments: a) Social Demographic Questionnaire, which inquired about information, like as age, schooling, length of study, marital status, religion, and clinical health characteristics, among other data; b) the Vulnerability to Abuse Screening Scale (VASS-Br), a 12-item tool used to measure the occurrence of violence. The total score varies from 0 to 12 , being indicated that scores above 3 are indicative of risk of violence and values higher than 7 points may suggest an already effective violence; ${ }^{7,8}$ c) the Geriatric Depression Scale (GDS-15) used to track symptoms of depression, with a score ranging from 0 to 15 points. Values from 6 to 10 indicate mild to moderate depressive symptoms, from 11 onwards indicate severe depression; and d) the Social Support Scale (EAS), composed of 19 items answered on a five-point likert scale. The score varies from 19 to 95 , considering that the higher the score, the greater the quality of the support network. 
The data were categorized and analyzed through descriptive and inferential statistics, using Student's t-test and Pearson's correlation. To effectuate the analyzes, a computerized software was used for the treatment of statistical data.

This project complied with the requirements of the Declaration of Helsinki and national laws about human research. The project was submitted to the National Commission for Research Ethics (CONEP), and approval was obtained for the development of the research (protocol number 97.186/2012).

\section{Results}

Most of the participants were women ( $\mathrm{n}=141,70.9 \%$ ), ranging from 60 to 84 years (M: 67.96; SD: \pm 6.45 ) living with one to eight

Table I Sociodemographic data of the surveyed elderly population

\begin{tabular}{|c|c|c|c|}
\hline \multirow{2}{*}{\multicolumn{2}{|c|}{ Variables }} & \multirow{3}{*}{$\begin{array}{l}f \\
|4|\end{array}$} & \multirow{3}{*}{$\begin{array}{l}\% \\
70,9\end{array}$} \\
\hline & & & \\
\hline \multirow{2}{*}{ Sex } & Female & & \\
\hline & Male & 58 & 29,1 \\
\hline \multirow{5}{*}{ Age group } & $60-64$ & 73 & 36,7 \\
\hline & $65-69$ & 58 & 29,1 \\
\hline & $70-74$ & 27 & 13,6 \\
\hline & $75-79$ & 25 & 12,6 \\
\hline & $80-84$ & 16 & 8 \\
\hline \multirow{2}{*}{$\begin{array}{l}\text { Marital status } \\
\text { (Married) }\end{array}$} & Yes & 145 & 72,9 \\
\hline & No & 54 & 27,1 \\
\hline \multirow{2}{*}{ Stay alone the most part of the day? } & Yes & 40 & 20,1 \\
\hline & No & 159 & 79,9 \\
\hline \multirow{4}{*}{ Scholarity } & Never studied & 14 & 7 \\
\hline & Elementary School & 60 & 30,2 \\
\hline & High School & 82 & $4 I, 2$ \\
\hline & Higher Education & 43 & 21,6 \\
\hline \multirow{2}{*}{ Do you have your own income, pension or retirement? } & Yes & 176 & 88,4 \\
\hline & No & 23 & 11,6 \\
\hline \multirow{2}{*}{ Family income } & $<2 \mathrm{MW}$ & 166 & 83,4 \\
\hline & $>2 \mathrm{MW}$ & 33 & 16,6 \\
\hline \multirow{2}{*}{ Inability to perform any activity for health reasons in the last six months? } & Yes & 32 & 16,1 \\
\hline & No & 168 & 83,9 \\
\hline \multirow{2}{*}{ Have you suffered falls in the past six months? } & Yes & 35 & 17,6 \\
\hline & No & 164 & 82,4 \\
\hline
\end{tabular}

Legend, variables ; socio demographic aspect investigated; f, absolute frequency; \%, percentage ; MW, minimum wages (IMW=R \$937,00). persons at home (M: 4, 07, DP: \pm 1.36$)$. Most of the participants are married $(\mathrm{n}=145,72.9 \%)$ and receive retirement income or pension $(\mathrm{n}=176,88.4 \%)$. The other characterization data of the sample can be observed in Table 1 .

Regarding the VASS-Br results, used to assess the risk of violence or violence established, the scoring ranged from 0 to 10 (M:3.72; $\mathrm{SD}: \pm 2.26)$. The prevalence of violence among the elderly in the investigated sample was $16 \%$ (value $\geq 7 ; n=31$ ). The mean score for social support was 85.95 (SD: \pm 11.65 ), which suggests a good perception about the quality of the support received from the network that supports it. For the depressive symptoms, the mean score was 4.45 (SD: \pm 2.36 ). Table 2 shows the correlation between the VASS-Br score with EAS and GDS-15 (Table 2). 
Table 2 Correlation between social support and depression with VASS-Br.

\begin{tabular}{llll}
\hline \multicolumn{3}{c}{ Variables } & \\
\hline VASS-Br & & GDS-I5 & EAS \\
\hline & $r$ & 0,540 & $-0,138$ \\
& $P$ & $<0,00 I^{*}$ & 0,510
\end{tabular}

Legend: r, pearson's correlation; $p$, value of the statistical significance of the test Pearson correlation; *: $p$ very significant value $(p<0.001)$

This data suggests that there is a strong and positive correlation between depressive symptoms and the risk of violence, in other words, as depressive symptoms increase, there is an increased risk for the elderly to become a victim of violence. On the other hand, there was no such behavior between social support and the risk of violence.

In this study, female participants predominated, which has been associated with their greater longevity in relation with the elderly men, as well as due to their greater attendance in health services and living spaces for the elderly. In the investigated population, a profile of older adults residing in multigenerational households predominates, and they stay for most of the day with adults sons or grandsons, compatible with the profile indicated in the literature. ${ }^{9}$

The prevalence found in this study is similar to estimates in other epidemiological studies, which suggest prevalences between $10 \%$ and $21 \%$ in national studies and $15 \%$ to $35 \%$ in international studies. ${ }^{4}$ These findings demonstrate that the phenomenon of violence is correlated with the presence of depressive symptoms, approaching with results obtained in other studies, which verified that the symptoms of depression were associated with a higher risk of violence among the elderly, especially for the elderly women.$^{10,11}$

Furthermore, social support did not show a statistically significant correlation with violence. This result is not based on data found in the literature, which showed a negative correlation between perceived social support and the risk of violence. ${ }^{10}$

\section{Conclusion}

The findings indicate the prevalence of violence and association with depressive symptoms, that result is similar to data already mentioned in the literature. However, it should be pointed out that such data may be under-reported, due to the aspects pointed out in the literature, such as proximity and/or kinship relationship of the aggressor with the victim or the dependency relations that exist in the victim-aggressor relationship. The multigenerationality of the home, found in this study, may have impacted the correlation between violence and social support.

\section{Acknowledgments}

None.

\section{Conflicts of interests}

The authors declared no potential conflicts of interest of this article.

\section{References}

1. Gallione C, Dal Molin A, Cristina FVB, et al. Screening tools for identification of elder abuse: a systematic review. J Clin Nurs. 2017;26(1516):2154-2176.

2. Oliveira AAV, Trigueiro DRG, Fernandes MGM, et al. Maus-tratos a idosos: revisão integrativa da literatura. Rev bras enferm. 2013;66(1):128133.

3. Correia TMP, Leal MCC, Marques APO, et al. Perfil dos idosos em situação de violência atendidos em serviço de emergência em Recife-PE. Rev bras geriatr gerontol. 2012;15(3):529-536.

4. Maia RS, Maia EMC. Prevalence of violence and related aspects: preliminary study of older adults. J Nurs UFPE On Line. 2015; 9(7):89618968.

5. Rodrigues CL, Armond JE, Gorios C. Agressões físicas e sexuais contra idosos notificadas na cidade de São Paulo. Rev bras. geriatr gerontol. 2015;18(4):755-760.

6. Garbin CAS, Joaquim RC, Rovida TAS, et al. Idosos vítimas de maustratos: cinco anos de análise documental. Rev bras geriatr. gerontol. 2016;19(1):87-94.

7. Maia RS, Maia EMC. Adaptação transcultural para o português (Brasil) da Vulnerability to Abuse Screening Scale (VASS) para rastreio da violência contra idosos. Cad Saúde Pública. 2014;30(7):1379-1384.

8. Maia RS, Maia EMC. Psychometric evidence of the transcultural adaptation of the vulnerability abuse screening scale (VASS) for the detection of violence against the elderly. Rev bras geriatr gerontol. 2016;19(6):958-969.

9. Ferreira CL, Santos LMO, Maia EMC. Resiliência em idosos atendidos na Rede de Atenção Básica de Saúde em município do nordeste brasileiro. Rev esc enferm. 2012;46(2):328-334.

10. Dong X, Beck T, Simon MA. The associations of gender, depression and elder mistreatment in a community-dwelling Chinese population: The modifying effect of social support. Arch Gerontol Geriatr. 2010;50(2):202208 .

11. Dantas RB, Oliveira GL, Silveira AM. Psychometric properties of the vulnerability to abuse screening scale for screening abuse of older adults. Rev Saúde Pública. 2017;51(1):1-10. 